\title{
The Effects of Differing Densities of Glossing on Vocabulary Uptake and Reading Comprehension
}

\author{
Elvenna Majuddin \\ School of Linguistics and Applied Language Studies \\ Von Zedlitz Building, Kelburn Parade \\ Victoria University of Wellington \\ E-mail:miss_elvenna@yahoo.com
}

Doi:10.7575/aiac.alls.v.5n.6p.132

URL: http://dx.doi.org/10.7575/aiac.alls.v.5n.6p.132
Received: 16/08/2014

Accepted: 06/10/2014

\begin{abstract}
This study investigated the effects of differing densities of glossing on the uptake of target words and the comprehension of idea units from a reading text. The focus was whether different densities of glossing would create trade-off effects. Thirty-three Malaysian ESL learners were assigned to three different conditions: high-density glossing, low-density glossing, and no-glossing. Three weeks after a vocabulary pretest the participants read a text under one of the conditions, and took a reading comprehension test and a vocabulary posttest. The results revealed that there were no trade-off effects between reading comprehension and uptake of the target words. However, the glossed words did appear to detract from the uptake of un-glossed vocabulary. The results also hinted at a trade-off effect between attention given to idea units containing glossed target words, and those that did not contain glosses. The findings suggested that teachers should be aware of potential side-effects of glossing.
\end{abstract}

Keywords: gloss, density of glossing, reading comprehension, vocabulary acquisition, trade-off effects, input enhancement

\section{Introduction}

In the field of second and foreign language learning, glosses are generally accepted as a means of aiding reading comprehension and vocabulary learning. Glosses have been defined as short definitions (Nation, 2002) as well as input modification (Ko, 2012). The value of glosses has not been strongly contested, as proven by the wide use of glossing in textbooks and other L2 instructional materials. The fact that research has repeatedly shown that glossing promotes incidental vocabulary learning (Yoshii, 2006; Watanabe, 1997; Jacobs, Dufon \& Hong, 1994; Ko, 2012) lends support to the use of glossing in $\mathrm{L} 2$ texts.

Having said that, there is an inconclusive body of research concerning the relationship between glossing and its role in facilitating reading comprehension. While some studies have found glossing to have positive effects on reading comprehension (Davis, 1989; Jacobs, 1994; Ko, 2005), others have shown that glossing made little or no difference (Jacobs, Dufon \& Hong, 1994; Joyce, 1997; Holley \& King, 1971; Johnson, 1982; Cheng \& Good, 2009).

The inconsistent results in regard to the effects of glossing on reading comprehension have been speculated to be partially attributed to the amount of glossing that was employed in each study (Cheng \& Good, 2009; Jacobs, 1994; Ko, 2012). If the theory that the working memory is a limited-capacity processing system (Barcroft, 2002; Ellis, 2001; VanPatten, 1996) is accepted, these conflicting results can be seen in a new light. Texts that employ more glossing could affect learners' comprehension negatively as they could only allocate a certain amount of attention at a time to one aspect of a language. Attention that can be allocated to comprehending a text could be usurped by the word learning process imposed by the glosses. As such, one of the goals of the present study was to investigate the effects of differing amounts of glossing (i.e., density of glossing on reading comprehension).

In addition, the present study also looked at the effects of differing densities of glossing on vocabulary acquisition. One of the conditions, which will be called the low-density condition, utilised both glossing and textual enhancement (i.e., bolding only), so it allowed for the investigation of whether the availability of glossing in some passages detracts from the uptake of vocabulary from the un-glossed passages. In essence, the present investigation aimed to look at the effects of glossing on both reading comprehension and vocabulary learning, as plenty of research concerning glossing often look at its effect on reading comprehension and vocabulary learning separately. The few studies in the print medium that have investigated the effects of glossing on both reading comprehension and vocabulary (Cheng \& Good, 2009; Holley \& King, 1971) revealed that glossing seemed to have a positive effect only on vocabulary learning, but not reading comprehension. It has also been posited that comprehension and learning might be two different processes (e.g., Lee \& VanPatten, 1995; Sharwood Smith; 1986). Rott (2007) echoes this argument as she suggests that the cognitive mechanism involved in the two processes may be in conflict. A trade-off effect may then be expected when L2 learners 
use glossing. The current study sought to investigate this by manipulating the density of glossing to assess whether there would be a trade-off effect between vocabulary uptake and reading comprehension.

Another goal of the present investigation was to assess whether a second trade-off effect would appear when glosses are available for only some parts of a passage. The presence of a textually enhanced target word and glossing in an idea unit could potentially attract readers' attention which may affect their retention and comprehension of the particular idea unit. This allocation of resources and attention could be at the expense of the comprehension of idea units that do not contain a glossed target words. In short, the present investigation aimed to assess the effects of differing densities of glossing on both vocabulary uptake and reading comprehension, and to shed light on whether a two-fold trade-off effects would arise as a result of the glossing conditions.

\section{Literature review}

\subsection{The effects of glossing on incidental vocabulary learning}

Studies on the effects of glossing on vocabulary learning have shown quite consistently that glossing is advantageous for reading-based vocabulary learning (Jacobs, Dufon \& Hong, 1994; Ko, 2012; Watanabe, 1997; Yoshii, 2006). The number of glosses seems to be a factor that influences the effectiveness of the intervention, however. This can be illustrated by a comparison of the following two studies. Ko (2012) investigated the effects of different types of glosses on the vocabulary acquisition of 90 South Korean college undergraduates who were enrolled in English conversation courses. The participants read a 602-word essay under one of the three conditions: L1 glosses, L2 glosses and no glosses. They then took an immediate vocabulary test to test their receptive vocabulary knowledge. The results revealed that both glossed conditions performed significantly better than the no-gloss group. This finding is consistent with that of Jacobs, Dufon and Hong (1994), which confirms the effectiveness of glossing on vocabulary learning. Ko (2012) also conducted a delayed vocabulary test four weeks after the immediate vocabulary test. Again, it was found that both groups under the glossed conditions scored higher than the no-gloss group. This result, however, is incongruent with Jacobs, Dufon and Hong's (1994) study, where the participants did not maintain retention. Ko (2012) attributed the difference partially to the number of target words that were glossed. Ko's (2012) study only had 16 glossed items in a 602-word text. Ko (2012) speculated that a high number of glosses creates too heavy a learning burden and that requiring learners to attend to a substantial number of words in one go may compromise the formation of durable memories. Therefore, the amount of glossing in a text warrants further investigation, as it may have an influence on how much vocabulary learning can take place. Furthermore, the amount of glossing also appears to have differing effects on reading comprehension.

\subsection{The effects of glossing on reading comprehension}

Research on the effects of glossing on reading comprehension has not produced consistent results. While some studies revealed that glossing facilitates reading comprehension (Davis, 1989; Huang, 2003; Jacobs, 1994; Ko, 2005), others have shown that glossing made little or no difference (Cheng \& Good, 2009; Holley \& King, 1971; Jacobs, Dufon \& Hong, 1994; Johnson, 1982; Joyce, 1997).

The varying amounts of glossing employed in these studies may have contributed to the conflicting findings on the efficacy of glossing in aiding reading comprehension. Studies such as Joyce's (1997) appear to suggest that reading comprehension is not significantly affected when a low amount of glossing is employed. In Joyce's (1997) study, a recall protocol task was used to determine whether glossing had effects on the participants' reading comprehension. An authentic text in French, was distributed to undergraduates who were native speakers of English. The participants, who were grouped according to the semester they were in, were assigned to one of these two conditions: L1 (English) marginal glosses and no glosses. The results showed that participants from the gloss groups did not recall significantly more than those in the no-gloss condition. The article used in the experiment contained 470 words, with $15 \mathrm{~L} 1$ glosses. On average, there was only one word glossed for every 30 words. Thus, it may be argued that a limited number of glosses resulted in no difference between the experimental and control groups.

At first glance, a higher number of glossing seems to lead to better comprehension. In Jacobs' (1994) study, the text used contained one glossed word for every nine words, which is a greater percentage compared to other studies. The 116 non-native participants read a Spanish text either with or without English glosses. The participants then wrote down as much of the text as they could recall. Participants who read the glossed text recalled approximately thirty percent more idea units compared to the control group. The researcher speculated that the positive effect on the reading comprehension may be due, in part, to the amount of glossing that was used in the text. This finding implies that a higher number of glosses facilitates reading comprehension more than when a low amount of glossing is used.

However, there is also empirical evidence that suggests that a high amount of glossing does not significantly enhance reading comprehension. Johnson's (1982) study, which is the only study to my knowledge that contains a similar amount of glossing as Jacobs' (1994) study, showed that participants who were not assisted by glossing performed as well as those who had access to glossing before and/or during the reading of the text. Johnson (1982) manipulated topic familiarity as well as vocabulary knowledge to assess their effects on reading comprehension. A total of 72 non-native speakers of English were assigned to four different groups randomly. The control group had no access to the vocabulary explanation, while the three experimental groups had access to the definitions of the target words before the reading, during the reading, and before and during the reading respectively. To measure reading comprehension, a sentence recognition task and written protocol in L2 were employed. Despite the high amount of glossing, the results showed no 
significant difference between the four groups. These conflicting results underscore the need for more investigation in regard to the effects of differing amounts of glossing on reading comprehension.

\subsection{The effects of glossing on vocabulary learning and reading comprehension}

Many studies have focused on the effects of glossing exclusively on either vocabulary learning or reading comprehension. Few studies have been done on the effects of glosses in print medium on both vocabulary learning and reading comprehension. In some of the studies that have attempted this (Cheng \& Good, 2009; Jacobs, Dufon \& Hong, 1994), glosses were proven to aid vocabulary uptake, but not reading comprehension. Cheng and Good (2009) recruited 265 Taiwanese non-English major undergraduates and divided them into four conditions: (a) Chinese glosses plus English example sentences; (b) Chinese in-text glosses; (c) Chinese marginal glosses, and (d) no glosses. The participants were of four different levels of proficiency. Participants who were of proficiency levels 1 to 3 read a text containing 207 words, while those of level 4 proficiency read a text with 343 words. Both texts had 16 glossed items, making the ratio of glossed words $1 / 13$ and 1/21, higher than that of Joyce's (1997) study, but lower than that of Jacob's (1994) and Johnson's (1982) study. To assess reading comprehension, multiple-choice questions were used. Participants also took an immediate vocabulary test. All three experimental groups scored significantly higher on the vocabulary test compared to the no-gloss group.

However, there was no significant difference for reading comprehension between the control group and the three experimental conditions. The researchers discussed the possibility that the number of glossed words $(n=16)$ could have been too high, and could have possibly contributed to the lack of positive effects of glossing on reading comprehension. They posited that the diversion of attention from the main idea to the word meanings might be the reason behind the lack of positive effects of glossing on reading comprehension. While this may be true, the construct validity of the test used to measure reading comprehension may be questionable. Five multiple-choice questions may not be an adequate instrument in measuring learners' comprehension. These are rather few test items to discriminate between participants' performance, especially as one needs to take the guess factor into account as well. The present investigation attempts to address this issue by using a greater number of test items to assess participants' reading comprehension.

While much research has speculated that the amount of glossing could be a variable that significantly affects reading comprehension and vocabulary acquisition, few studies have manipulated the amount of glossing in a text. Though there have been studies that investigate the effects of different frequency of target words (e.g., Rott, 2007; Ekhert \& Tavakoli, 2012; Waring and Takaki, 2003; Webb, 2007) there is a dearth of research on the effects of different density (i.e., numbers of new words glossed) of glossing on both reading comprehension and vocabulary acquisition in the print medium. To my knowledge, Holley and King's (1971) research is the only known study that has strived to do so.

Holley and King (1971) defined density as the ratio of new to known words. Their study manipulated the location as well as the density of the glossing. The participants, non-native speakers of German, read an adapted German text which was 750 -words long. One version of the text contained 50 glossed new vocabulary items, while another had only 25 of the 50 words glossed, making the glossing ratio $1 / 15$ and 1/30 respectively. Per high-density and low-density gloss condition, the glosses were presented either at the side of the passage, or at the bottom of the page, or in an attached list. The participants were randomly assigned to one of these six groups. After reading the assigned text, the participants took a multiple-choice vocabulary test in German, and a reading comprehension test that consisted of 10 items in English. The results found that there was no significant difference between the groups as far as reading comprehension is concerned. Neither the number of glosses nor the location of the glosses appeared to be variables that significantly affect text comprehension. Participants who had 50 words glossed scored higher in the vocabulary test compared to those who had only half of that number of words glossed, but there was no significant effect of the location of the glosses. The conclusion that Holley and King (1971) drew from the results was surprising, however. They concluded that glossing neither significantly facilitates nor hampers the acquisition of new vocabulary, even though the results of the vocabulary test showed that those who had 50 glosses scored almost double the mean score of those who received only 25 glosses. They probably intended to say that the position of the glosses made no difference.

In any case, it should also be pointed out that there was no tight control over the pre-knowledge of the vocabulary or glossed items. Though vocabulary items that were chosen to be glossed were words that did not appear in the first-year textbook or the Minimum Standard German Vocabulary starred list, it is not known whether participants' knowledge of the target items was equivalent, as the participants were from different class sections. A vocabulary pre-test would have strengthened the findings, as learning gains between pre-test and post-test would have shed more light on the effects of the density and location of glosses. In the present investigation, a pre-test was employed to assess the effects of different densities of glossing on both reading comprehension and vocabulary learning. Particular attention was given to the possibility that glossing affects vocabulary uptake and reading comprehension differently.

\subsection{Textual enhancement and trade-off effects}

There are grounds for suspecting that there could be a trade-off effect between reading comprehension and vocabulary learning, when the latter is encouraged by the presentation of glosses. Apart from the studies reviewed here which reported that glossing seems to have little or no effect on reading comprehension, research on cognition in general has shown that there are limits to allocation of attention (Cowan, 2005), and that the working memory is a limited-capacity processing system (Barcroft, 2002; Ellis, 2001; Skehan, 1996; VanPatten, 1996). It is conceivable that directing second language readers' attention to selected words and their definitions/L1 equivalents may detract from the attention which 
the readers might otherwise give to interpreting the text. If so, glossing would be expected to be beneficial for vocabulary uptake, but this benefit would come at the expense of text comprehension.

It has also been proposed that comprehension and learning are two different phenomena (Lee \& VanPatten, 1995; Sharwood Smith, 1986). Rott (2007) has also suggested that the cognitive mechanisms involved in the two processes may even be in conflict. Thus, glossing may have positive effects on one of the aspects, but debilitating effects on another.

The fact that the glossed words are often bolded in passages may also affect participants' allocation of attention to reading comprehension. Previous research on textual enhancement on reading has demonstrated that the bolding of target words has negative effects on reading comprehension (Lee, 2007; Overstreet, 1998). Lee (2007) investigated the effects of textual enhancement and topic familiarity on Korean EFL learners' acquisition of grammatical form and meaning comprehension. The results found that though the participants who were presented with the enhanced text attended to the target grammar, they recalled significantly less compared to those who were given the unenhanced text. This result corroborated Overstreet (1998)'s study, which reported that textual enhancement has a detrimental effect on comprehension. Lee (2007) posited that even the relatively non-obtrusive intervention of textual enhancement may be unfavourable for drawing learners' attention to the content of a text. If so, then one might expect that the bolding and glossing of target words, which is what is done in the present study, will usurp learners' attention even more.

A related study by Rott (2007), however, suggests that bolding and glossing positively influence text comprehension. In her study, Rott (2007) manipulated the frequency of enhanced target words on word learning and text comprehension. A total of 54 learners of German, who were native speakers of English, read three adapted German texts under one of the three different conditions: (a) target words were glossed four times in the text $(4 \mathrm{G})$; (b) target words were first glossed and then retrieved in the L1, and bolded twice (GR); and (c) target words were first glossed, and then bolded three times (GB). To further investigate whether the learning of words is significantly affected by the repeated encounters (i.e., frequency of repetition), some of the target words appeared only once (F1), while others appeared four times (F4). The effects of all the different treatments on reading comprehension was also investigated as participants were required to retell the content of the passage as completely as possible in their L1. The vocabulary test revealed that participants in the GR and 4G groups outperformed the GB treatment. It was also found that the comprehension of main ideas was the best when the target words were glossed four times.

Rott's (2007) findings were particularly interesting as she found that when learners were provided with repeated meanings of a target word, both their comprehension and word learning were enhanced. Rott (2007) also concluded that glosses directly influence text comprehension by making propositional content easier to access while raising awareness of the importance of propositional context. It is important to interpret this result with caution, as in Rott's (2007) study many target words were glossed more than once. A gloss may usurp less attention when it is re-encountered and so more attention may, in that case, be given to the entire proposition in which the word occurs. In the textbooks that I am familiar with, glossing is commonly used but target words are typically glossed only once. How vocabulary uptake interacts with uptake of propositional content in a reading condition with single appearances of glossed target words still merits investigation. This is what the current study aims to do: to investigate whether the presence of a target word glossed only once affects vocabulary learning and reading comprehension.

The present investigation also seeks to expand Rott's (2007) line of investigation by comparing learners' comprehension of idea units that contained a glossed target word, with ones that did not. One may indeed expect that students will assume the glosses have been made available by the materials writer because the text passages they accompany are deemed to be comparatively important ones in the text. As a result, the students may give less attention to the non-glossed passages ( $c f$. Schmidt $(1994,1995,2001)$ on the crucial role of attention). The presence of glossing would thus stimulate more engagement with the idea unit and this would result in better intake of both the target word and the propositional content. Besides, the presence of glosses facilitates comprehension, and comprehension is a prerequisite for adequate intake of propositional content. Even if the students were to give an equal amount of attention to un-glossed text passages, they may fail to fully comprehend these due to the presence of unfamiliar words.

On the other hand, it could also be argued that glossing provides an easier access to the passage, which could then minimize the readers' need to invest cognitive effort in its interpretation. If so, the propositional content is perhaps less likely to leave a durable memory trace in comparison to text passages that come without facilitative glosses and where the students thus need to invest a greater interpretation effort. In this regard, it is likely that glossing affects processing differently from typographic enhancement alone. It is conceivable that an idea unit containing a textually enhanced target word, sans glossing, promotes a deeper engagement because the unavailability of glossing would force the readers to resort to using contextual clues. This cognitive effort - when it leads to successful interpretation - could help retention of the idea units. As postulated by the Involvement Load Hypothesis (Laufer \& Hulstijn, 2001), better learning could result from a higher level of processing load. Though mainly used for incidental vocabulary learning, this theory could be extrapolated to the processing of content as well.

In short, the availability of glossing could result in differing levels of engagement and retention. This retention could then be at the expense of retention of other idea units. In essence, this current study sought to investigate whether a second trade-off effect between comprehension of glossed and un-glossed idea units would arise.

For purposes of this study, reading comprehension is operationalised as successful short-term retention of idea units as shown through learners' responses to post-reading multiple-choice questions. As the participants in the current 
investigation did not have the reading texts at their disposal anymore during this reading comprehension test, it is not only comprehension as such but also short term retention that is being tested. If glossing, coupled with textual enhancement is expected to increase participants' attention, then measuring their retention is appropriate as eye-tracking studies (Godfroid, Boers, \& Housen, 2013) have shown that amount of attention correlates with retention of what was attended to. Attention that is shown through retention also presupposes comprehension, as intake is a consequent product of attention (Wong \& Simard, 2000). Empirical studies on grammar acquisition have also shown that increased attention results in increased learning (Leow, 1997, 2001; Rosa \& O’Neill, 1999).

\section{Research questions}

The present investigation seeks to expand Rott's (2007) line of investigation by (a) comparing learners' uptake of glossed and un-glossed words under different glossing conditions and (b) comparing learners' comprehension of idea units that contained a glossed target word with ones that did not. Following the example of Holley and King (1971), this current study also aims to investigate the effects of different densities of glossing on both reading comprehension and vocabulary learning in order to ascertain whether both can be enhanced at the same time, without a trade-off effect.

Participants were assigned to read a text containing ten target words under one of these conditions: (a) all 10 target words glossed (high-density), (b) only 5 of the target words glossed (low-density), and (c) none of the target words glossed (no-gloss or control condition). In this regard, this study can be said to be a partial replication of Holley and King's (1971) study. Specifically, the current study addresses the following research questions:

1. What is the effect of each glossing condition (high-density, low-density, and no-gloss) on participants'

(a) uptake of the ten target words?

(b) uptake of the five target words that were glossed in both high-density and low-density glossing conditions?

(c) uptake of the five target words that were glossed only in the high-density glossing condition?

2. What is the effect of each glossing condition (high-density, low-density and no-gloss) on participants'

(a) overall comprehension of the text?

(b) performance on reading comprehension questions concerning idea units that contained a target word only glossed in the high-density condition?

(c) performance on reading comprehension questions concerning idea units that contained a target word glossed in both the high-density and low-density conditions?

(d) performance on reading comprehension questions concerning idea units that did not contain a target word across conditions?

3. Do the scores on tests show evidence of a trade-off effect between uptake of glossed vocabulary and text comprehension in general?

4. Does the availability of glosses for some passages of a text detract from intake of vocabulary from un-glossed passages?

5. Does the availability of glosses for some passages of a text detract from intake of content from un-glossed passages?

On the basis of results of previous studies that reported the facilitative role of glossing on incidental vocabulary learning (Yoshii, 2006; Watanabe, 1997; Jacobs, Dufon \& Hong, 1994; Ko, 2012), I hypothesize that participants in the highdensity group will record the highest uptake of the target words. Following the same rationale, I expect the five words glossed only in the high-density group will be learnt best by the participants under the same condition. For the other five target words that were glossed both in the high-density and low-density conditions, I expect the low-density condition to perform best as their attention was not spread between 10 target words. The no-gloss condition is expected to record the lowest uptake of the target words.

As for the second and third research questions, I make no predictions, because previous studies have yielded inconsistent results. On the one hand, it is possible that the more glossed target words the participants have access to, the worse they will perform in the reading comprehension test. This is based on the theory of limited-capacity processing system, as well as results of some of the previous studies on glossing (Johnson, 1982; Jacobs, Dufon \& Hong, 1994; Joyce, 1997; Holley \& King, 1971; Cheng \& Good, 2009) and textual enhancements (Lee, 2007; Overstreet 1998) that reported little or no positive effects on reading comprehension. On the other hand, comprehension is a prerequisite for adequate intake of propositional content. Centrality of vocabulary for comprehension is a widely accepted theory, and knowing word meaning is instrumental, or enables, reading comprehension in a causal way (Freebody \& Anderson, 1983). Thus, though I predict a trade-off between vocabulary uptake and reading comprehension, I questioned whether the hypothesis will be borne out.

Extending the rationale of limited processing capacity and theory of noticing to research questions 4 and 5 , I hypothesize that the presence of glossing for some passages will not only detract intact of vocabulary, but also intake of content, from un-glossed passages.

\section{Method}

\subsection{Participants}

The participants in this study were 33 Malaysian primary school learners who were all aged 11. Of the 33, 20 were Chinese with Mandarin as their L1. The rest of the participants, nine of whom were Malay, and four of whom were indigenous, were native speakers of Malay. All the participants, who came from an intact in a Chines public school, 
have received formal English language instruction for at least 6 years. Consent from the participants and their parents was obtained on a signed form.

\subsection{Materials}

Two texts were chosen and modified for this experiment (Appendix 1). The texts were taken from a workbook that was part of the participants' class materials. The English teacher was consulted for the purpose of evaluating the difficulty level and the topic of the texts, so as to minimize the effect of topic familiarity. Topic familiarity could affect the learners' comprehension, as they might have content knowledge that they could draw on (Chen \& Donin, 1997; Johnson, 1982; Ko, 2012).

The two texts dealt with topics that were believed to be unfamiliar to the participants, on account that they focus on a type of fruit and a celebration that only exists in West Malaysia. The East Malaysian participants were expected to have low or no knowledge of these topics. The first text was 203 words long, while the second text was 166 words long.

\subsection{The glossed words}

The glossed words were chosen by conducting a vocabulary pre-test. Results from the pre-test narrowed down the ten words that were to be glossed. The target words appeared boldfaced in the text. The glosses, which were synonyms or short definitions, were provided at the bottom of the page and arranged according to the order of appearance in text. Since the participants have different L1s, the glosses in the present investigation were in L2, which was English. The glosses were incorporated in some of the passages only. This was because some of the reading comprehension questions were based on passages where the target words had been glossed, as well as those where the target words had not been glossed.

\subsection{The tests}

\section{Vocabulary Pre-test}

The vocabulary pre-test (Appendix 2) was in the format of multiple-choice questions. The 20 words chosen to be tested included words that were already glossed in the original text itself, as well as words that were thought to be unknown to the students. Words that the researcher expected the learners to know were also included in the vocabulary pre-test, as it benefited the ecological validity of the test. The English teacher was also consulted when choosing the 20 words as she knew the participants' vocabulary knowledge better. The words that were known by more than $40 \%$ of the participants were eliminated, leaving only 12 target words. Of the 12 words, 10 were chosen as the target words to be glossed, while the other two words were replaced by a simplified word since research has shown that at least $98 \%$ percent of coverage is needed for adequate comprehension (Hu and Nation, 2000). Therefore, replacing the two words with simplified versions increased the likelihood that no words, except for the target words, were unknown to the participants.

\section{Reading Comprehension Test}

The participants completed a reading comprehension test that consisted of 12 multiple-choice questions (Appendix 3). The questions were based on idea units that contained target words that were glossed, as well idea units without accompanying glosses. In the first experimental group, eight out of the twelve questions were based on idea units that contained a glossed target word. In the second experimental group, only four of the questions were based on idea units that contained a glossed target word, since the participants had access to glossing for only half of the target words. In the control group, all of the questions were based on idea units that contained un-glossed target words, since the participants read the passages without the aid of glosses.

\section{Immediate Vocabulary Posttest}

This study operationalises the uptake of vocabulary as in as far as the participants are able to recognize the meaning of the target vocabulary. In other words, this study assesses participants' receptive word knowledge gain. As such, the format of the immediate vocabulary posttest was similar to the pretest. The order of the items and the answer options were randomized (Appendix 4).

\subsection{Testing procedure}

Data was collected over a period of three weeks with the help of the participants' English teacher. After their consent was obtained, the participants were given the vocabulary pre-test to measure their knowledge of the target words. Three weeks later the actual experiment was administered. The participants were randomly assigned to one of the three conditions: high-density glossing $(n=11)$, low-density glossing $(n=11)$, and no-gloss $(n=11)$. The texts were distributed to the participants, who were given 10 minutes to read the texts as many times as they wanted to. After 10 minutes, the texts were collected and the participants completed the reading comprehension test. The test took 15 minutes. This was immediately followed by an unexpected vocabulary test, which took 15 minutes.

\subsection{Scoring procedure}

1 point was given for each correct answer for the reading comprehension and both vocabulary tests. The maximum score for the reading comprehension test was 12 , while 20 was the maximum score for both the vocabulary pretest and posttest.

\section{Results}

Table 1 shows the vocabulary pretest and posttest scores for the 10 target words, as well the gains in scores for all the conditions. The results of the vocabulary pretest, as presented in Table 1, showed that the three groups were not 
perfectly equivalent in their prior knowledge of the ten target words. Participants in the control group scored slightly higher compared to the other two groups. Although a one-way analysis of variance (ANOVA) indicates that the difference is not statistically significant $(F 1.68, p 0.20)$, it was deemed cautious to compare the groups' gains between pretest and posttest rather than the raw posttest scores as such. So, to answer research question 1 (a), what needs to be taken into account is each participant's gains in score between the vocabulary pretest and posttest. As shown in Table 1, the gains in mean score were actually higher for the low-density compared to the no-gloss condition. The highest gain in mean score, which was 4.40, was reported for the high-density group. ANOVA also revealed that there were statistically significant differences among the three different conditions $(F 6.16, p 0.006)$. These findings corroborate the hypothesis put forward earlier. Tukey post-hoc also showed that significant differences lie between the high-density and low-density conditions $(p<0.5)$, as well as between the high-density and no-gloss conditions $(p<0.1)$. No significant difference was observed between the low-density and no-gloss conditions.

Table 1. Means and standard deviations of vocabulary pretest, posttest and word gains for the 10 target words

\begin{tabular}{|c|c|c|c|c|c|c|}
\hline & \multicolumn{6}{|c|}{ Conditions } \\
\hline & \multicolumn{2}{|c|}{ High-density } & \multicolumn{2}{|c|}{ Low-density } & \multicolumn{2}{|c|}{ No-gloss } \\
\hline & $M$ & $S D$ & $M$ & $S D$ & $M$ & $S D$ \\
\hline $\begin{array}{c}\text { Vocabulary } \\
\text { Pretest }\end{array}$ & 2.50 & 2.12 & 2.40 & 1.42 & 3.63 & 1.56 \\
\hline $\begin{array}{c}\text { Vocabulary } \\
\text { Posttest }\end{array}$ & 6.90 & 2.28 & 3.60 & 2.59 & 3.81 & 2.27 \\
\hline $\begin{array}{c}\text { Gains in } \\
\text { score }\end{array}$ & 4.40 & 2.41 & 1.20 & 2.39 & 0.18 & 2.60 \\
\hline
\end{tabular}

Research Question 1(b) investigated the uptake of the five target words that were glossed in both the high-density and low-density glossing conditions. Table 2 reports the means and standard deviations. While the gain scores for the participants under the no-gloss condition were in keeping with the hypothesis, the gain scores for the two experimental conditions did not corroborate the hypothesis. Participants under the high-density condition performed better than those in the low-density condition. Contrary to the initial assumption, participants in the high-density condition were able to retain the meanings of these five target words better compared to the low-density condition, even though the latter condition did not prompt students to direct their attention resources to an additional five words. ANOVA also revealed that the differences among the three different conditions approaches significance $(F 3.2, p 0.056)$.

Table 2. Means and standard deviations of vocabulary pretest, posttest and word gains for the five target words that were glossed in both experimental groups

\begin{tabular}{|c|c|c|c|c|c|c|}
\hline & \multicolumn{6}{|c|}{ Conditions } \\
\hline & \multicolumn{2}{|c|}{ High-density } & \multicolumn{2}{|c|}{ Low-density } & \multicolumn{2}{|c|}{ No-gloss } \\
\hline & $M$ & $S D$ & $M$ & $S D$ & $M$ & $S D$ \\
\hline $\begin{array}{c}\text { Vocabulary } \\
\text { Pretest }\end{array}$ & 1.50 & 1.50 & 1.10 & 0.99 & 1.63 & 1.12 \\
\hline $\begin{array}{c}\text { Vocabulary } \\
\text { Posttest }\end{array}$ & 3.60 & 1.07 & 2.10 & 1.66 & 2.09 & 1.37 \\
\hline $\begin{array}{c}\text { Gains in } \\
\text { score }\end{array}$ & 2.10 & 2.84 & 1.00 & 2.88 & 0.46 & 2.07 \\
\hline
\end{tabular}

Table 3 shows the means and standard deviations for the other set of five words, glossed only in the high-density condition. As shown in the table, the high-density glossing group showed the highest gains in mean scores between the vocabulary pretest and posttest. This corroborates the hypothesis as this set of five words was only glossed in this condition. The follow-up with ANOVA also revealed that there was a significant difference among the three glossing conditions ( $F$ 9.81, $p$ 0.0005). The gains in mean score for the low-density and no-gloss conditions, however, were somewhat unexpected as the participants in both groups achieved the same negative value of -0.10 in marks gained. They performed slightly worse in the vocabulary posttest compared to the pretest, though the decrease in marks was minimal. Tukey post-hoc test revealed that the significant differences lie between the high-density and low-density conditions $(p<0.1)$, and between the high-density and no-gloss conditions $(p<0.1)$. No significant difference was found between the low-density and no-gloss conditions. 
Table 3. Means and standard deviations of vocabulary pretest, posttest and word gains for the five target words that were glossed only in the high-density condition

\begin{tabular}{ccccccc}
\hline & \multicolumn{7}{c}{ Conditions } \\
\cline { 2 - 7 } & $M$ & $S D$ & $M$ & $S D$ & \multicolumn{2}{c}{ No-gloss } \\
& 0.90 & 0.87 & 1.60 & 1.07 & $M$ & $S D$ \\
$\begin{array}{c}\text { Vocabulary } \\
\text { Pretest }\end{array}$ & & & & 2.00 & 1.18 \\
$\begin{array}{c}\text { Vocabulary } \\
\text { Posttest }\end{array}$ & 3.50 & 1.43 & 1.50 & 1.26 & 1.90 & 1.30 \\
$\begin{array}{c}\text { Gains in } \\
\text { score }\end{array}$ & 2.60 & 1.42 & -0.10 & 1.52 & -0.10 & 1.75 \\
\hline
\end{tabular}

Research question 2(a) assessed the effects of each glossing condition on participants' reading comprehension. Table 4 shows the means and standard deviations of participants' score on the overall reading comprehension test. Participants in the high-density condition achieved the highest mean score, which was 8.81 out of the maximum 10 marks. This finding is inconsistent with the hypothesis which predicted that the more glosses participants had access to, the worse they would perform in the comprehension test. Participants in the low-density condition, however, did have a lower mean score compared to those in the no-gloss condition. ANOVA also indicated that there were significant differences among the three different conditions ( $F$ 9.23, $p$ 0.0007). Tukey post-hoc test further revealed that the significant differences lie between the high-density and low-density conditions, as well as between the high-density and no-gloss conditions. No significant difference was found between the low-density and no-gloss conditions.

Table 4. Means and standard deviations of overall reading comprehension test

\begin{tabular}{|c|c|c|c|c|c|c|}
\hline & \multicolumn{6}{|c|}{ Conditions } \\
\hline & \multicolumn{2}{|c|}{ High-density } & \multicolumn{2}{|c|}{ Low-density } & \multicolumn{2}{|c|}{ No-gloss } \\
\hline & $M$ & $S D$ & $M$ & $S D$ & $M$ & $S D$ \\
\hline Reading & 8.81 & 2.08 & 4.54 & 2.87 & 6.09 & 2.02 \\
\hline $\begin{array}{c}\text { Comprehension } \\
\text { Scores }\end{array}$ & & & & & & \\
\hline
\end{tabular}

The same trend appeared for the participants' scores for the four questions concerning idea units that contained a target word glossed in both the high-density and low-density conditions. As shown in Table 5, the high-density condition recorded the highest mean score, which was 3.09, followed by the no-gloss condition with a mean score of 2.00 . The low-density condition had yet again the lowest mean score, despite having had access to glossing. ANOVA also yielded statistically significant difference among the conditions $(F 4.53, p 0.01)$. A post-hoc Tukey test showed that the highdensity and low-density conditions differed significantly at $p<.05$, while the no-gloss condition was not significantly different from the other two conditions.

Table 5. Means and standard deviations of reading comprehension scores for questions concerning idea units that contained a target word glossed in both the high-density and low density conditions

\begin{tabular}{ccccccc}
\hline & \multicolumn{9}{c}{ Conditions } \\
\cline { 2 - 7 } & \multicolumn{2}{c}{ High-density } & \multicolumn{2}{c}{ Low-density } & \multicolumn{2}{c}{ No-gloss } \\
Reading & $M$ & $S D$ & $M$ & $S D$ & $M$ & $S D$ \\
Comprehension & 3.09 & 0.83 & 1.81 & 1.32 & 2.00 & 1.00 \\
Scores & & & & & & \\
\hline
\end{tabular}

Research question 2(c) investigated the effects of each glossing condition on participants' performance on the questions concerning idea units that contained a target word glossed only in the high-density condition. As shown in Table 6, the trend was in the same direction as the first set of four questions. The high-density group achieved the highest mean score, while the no-gloss condition outperformed the low-density gloss group once again. The follow up with ANOVA also showed that statistically significant differences exist among the three conditions $(F 10.83, p 0.0002)$. Tukey posthoc comparisons of the three groups further indicated that the significant differences lie between the high-density and low-density groups $(p<0.1)$, as well as between the low-density and no-gloss groups $(p<0.5)$. No significant difference was found between the high-density and no-gloss conditions. 
Table 6. Means and standard deviations of reading comprehension scores for questions concerning idea units that contained a target word glossed only in the high-density condition

\begin{tabular}{ccccccc}
\hline & \multicolumn{9}{c}{ Conditions } \\
\cline { 2 - 7 } & \multicolumn{2}{c}{ High-density } & \multicolumn{2}{c}{ Low-density } & \multicolumn{2}{c}{ No-gloss } \\
Reading & 3.09 & 0.83 & 1.27 & 1.00 & 2.27 & 0.90 \\
Comprehension \\
Test
\end{tabular}

Research question 2(d) determined participants' performance on questions concerning idea units that did not contain any target words across the three conditions. As shown in Table 7, the trend prevailed. The highest gains in mean score, 2.63, was found for the participants in the high-density condition. The participants in the no-gloss condition achieved a mean score of 1.91, which is higher by 0.37 marks compared to the low-density group. ANOVA also confirmed that there were significant differences among the three groups $(F 3.68, p 0.03)$. A follow up with post-hoc Tukey test indicated that the significant differences were only present between the high-density and low-density groups $(p<0.5)$. In general, the effects of each glossing conditions on reading comprehension yielded results that were inconsistent with the hypothesis that more glossing will lead to poorer comprehension.

Table 7. Means and standard deviations of reading comprehension scores for questions on idea units that do not contain target words across all conditions

\begin{tabular}{ccccccc}
\hline & \multicolumn{9}{c}{ Conditions } \\
\cline { 2 - 7 } & \multicolumn{2}{c}{ High-density } & \multicolumn{2}{c}{ Low-density } & \multicolumn{2}{c}{ No-gloss } \\
& $M$ & $S D$ & $M$ & $S D$ & $M$ & $S D$ \\
Reading & 2.63 & 1.02 & 1.54 & 1.03 & 1.91 & 0.87 \\
$\begin{array}{c}\text { Comprehension } \\
\text { Test }\end{array}$ & & & & & \\
\hline
\end{tabular}

Research question 3 assessed whether there was any trade-off effect between the uptake of glossed target words and reading comprehension. As discussed above, the high-density condition recorded the highest gains in mean score between the vocabulary pretest and posttest, as well as the highest score in the reading comprehension test. Pearson product-moment correlation coefficient also showed that there was a positive correlation between the participants' vocabulary uptake and reading comprehension $(r 0.47, n 33, p 0.0052)$. Thus, contrary to the initial assumption, no trade-off effects were observed, since there was a positive correlation between vocabulary uptake and reading comprehension.

Research question 4 investigated whether the availability of glosses in some passages detracts from uptake of vocabulary from un-glossed passages. To answer this question, a two-way repeated measure ANOVA was conducted for the low-density and no-gloss conditions, with the gloss condition as the between-group factor, and the uptake of the five glossed and the five un-glossed target words as the within-group repeated factor. A close-to significant interaction was found $[F(1,3.84)=4.27, p 0.051]$. This suggests that the glossing positively affected uptake of the five glossed words but adversely affected uptake of the five non-glossed words.

Research question 5 assessed whether the availability of glosses for some passages detracts from intake of content from un-glossed passages. If we look at Table 8 , it is clear that for participants in the experimental groups, the scores for questions on passages containing glosses were higher as opposed to their scores on passages that did not contain glosses. The high-density condition, for example, achieved a mean score of 3.09 for the two sets of four questions on idea units that contained glosses. In comparison, their score for the four questions that did not contain glossing was only 2.63. The same trend appeared for the participants in the low-density condition. Their mean scores on the four questions concerning idea units that contained glosses were higher compared to the other questions on idea units that did not contain glosses. As for the no-gloss condition group, due to the absence of glossing, their attention seemed to be spread out quite evenly. Their scores on the three sets of questions, which were 2.27, 2.00 and 1.91 respectively, did not differ that much.

The raw data seems consistent with the hypothesis, as the high-density and low-density conditions' scores were higher for the questions on glossed idea units compared to the un-glossed idea units. A two-way ANOVA with repeated measure on one factor was also conducted to determine whether there was a statistical significance between the lowdensity and the no-gloss condition for the performance on the questions concerning glossed and un-glossed idea units. The glossing was the between-subjects variable, while the scores on the questions based on the four glossed and the eight un-glossed idea units were the within-subjects variable. The results showed that there was an interaction that approaches significance $[F(1,3.27)=3.37, p 0.08]$. This suggests that glossing positively affects intake of idea units that come with a gloss, but adversely affects intake of the other idea units of the text, which do not come with a gloss. This hints at the possibility of a trade-off effect between the comprehension of idea units that contained a glossed target 
word, and those that did not contain a glossed target word. The data needs to be interpreted with caution, of course. Not only was the number of students per condition small, the number of test items concerning glossed and un-glossed idea units was also small.

Table 8. Means scores for the three sets of reading comprehension questions

\begin{tabular}{|c|c|c|c|}
\hline \multirow[t]{2}{*}{ Reading comprehension questions } & \multicolumn{3}{|c|}{ Conditions } \\
\hline & High-density & Low-density & No-gloss \\
\hline $\begin{array}{l}\text { On idea units that contained a target word glossed only in } \\
\text { high-density condition }\end{array}$ & 3.09 & 1.27 & 2.27 \\
\hline $\begin{array}{l}\text { On idea units containing a target word glossed in both } \\
\text { high-density and low-density conditions }\end{array}$ & 3.09 & 1.81 & 2.00 \\
\hline $\begin{array}{l}\text { On idea units that do not contain a target word across } \\
\text { conditions }\end{array}$ & 2.63 & 1.54 & 1.91 \\
\hline
\end{tabular}

\section{Discussion}

In line with previous research that reported the effectiveness of glossing in promoting incidental vocabulary learning, it was predicted that glossing would help the participants learn more words. The statistical analyses revealed that glossing indeed brought about better performance in terms of gains in mean scores between the vocabulary pretest and posttest. It was also observed that the higher the number of target words glossed, the higher the gains in mean scores. Thus, it can be inferred that more glossing leads to more target words learned. The results not only predict the hypothesis, but also confirmed the results of previous studies that reported glosses facilitative effects on incidental vocabulary learning (Jacob, Dufon \& Hong, 1994; Ko, 2012; Watanabe, 1997; Yoshii, 2006).

The theory of limited-capacity processing system (Barcroft, 2002; Ellis, 2001; VanPatten, 1996), as well as the empirical evidence from previous studies on glossing that witness little or no positive effects on reading comprehension (Jacobs, Dufon \& Hong, 1994; Holley \& King, 1971; Joyce, 1997; Johnson, 1982; Cheng \& Good, 2009) led to the prediction that there would be a trade-off effect between reading comprehension and vocabulary uptake. Hence, it was expected that participants who had their attention usurped by the 10 glossed target words would perform worse in the reading comprehension test. The results, however, did not bear out the hypothesis. It appeared that the provision of 10 glossed target words aided reading comprehension quite significantly. Positive effects, though to a lesser degree, were also seen for participants who had access to only half of the glosses. Though this corroborated previous findings on the facilitative effects of glossing on reading comprehension (Davis, 1989; Jacobs, 1994; Ko, 2005), it ran counter to Cheng and Good (2009) and the other aforementioned studies that report the absence of, or the limited positive effects of glossing on reading comprehension.

There are several plausible reasons as to why the current investigation's results were not in accordance with some previous studies that found glossing to be ineffective as a means of aiding comprehension. One possible reason is the method used in assessing comprehension. As posited by Davis (1989), the choice of dependent measure could partially account for the mixed findings. As discussed in the Literature Review section, retention has a hand in influencing the learners' performance in the reading comprehension test. The multiple-choice questions that provided options could have helped learners to recall better what was retained in their short-term memory, as the options might have jogged the participants' memory. Thus, the multiple-choice items employed as a measure of comprehension in this study could have contributed to the more positive result, compared to when a different measure such as a recall protocol is used. Another factor that might have intervened in the present study was the use of more items to assess participants' reading comprehension. Cheng and Good's (2009) study, for example, used only five items to assess participants' comprehension. In contrast, the current investigation employed 12 questions. More items ensures a more adequate measure of comprehension, which would discriminate among the participants more effectively.

The importance of glosses to the understanding of idea units might also be a factor. As Ko (2005) puts it, if the glosses are paramount to the comprehension of a text, then they evidently play an important role. This echoes Jacobs' (1994) argument, who posited that comprehension is significantly affected by glosses that are relevant to the meaning of a text. In the present investigation, care had been taken to ensure that the glosses were crucial to the understanding of the idea unit. This would explain why in this study glossing appeared to be more effective as a means of facilitating comprehension.

While all the reasons mentioned above provide plausible explanations for the high performance of the high-density condition and the acceptable performance of the low-density condition, they do not account for the performance of the participants in the no-gloss group. Unexpectedly, the participants in the no-gloss condition achieved an even higher score in the reading comprehension test compared to those of the low-density condition. There are a few viable explanations. Firstly, it could be that the participants in the control group relied on other strategies to help them comprehend the passages. They may have resorted to using an array of reading strategies to help them comprehend 
better since they did not have access to the glosses. This assumption is supported by Ko (2005), whose study found that participants who read texts without glosses used more strategies compared to those who read texts with the aid of L1 and L2 glossing. Ko's (2005) qualitative data showed that participants who read texts under the no-gloss conditions monitored their comprehension regularly owing to uncertain comprehension. Thus, it could be speculated that the participants in the no-gloss condition were successful in using reading strategies so much so that their performance in the reading comprehension text surpassed those who had access to the five target words.

Another possible reason behind the superior performance of the no-gloss condition over the low-density condition could be the slightly lower proficiency level of the latter group. As the vocabulary pretest results have shown, participants in the no-gloss condition seemed to be slightly more proficient than the low-density group. Thus, some of participants may not have needed the glosses as much as others did. This supposition is supported by Cheng and Good (2009), who argued that not all levels of proficiency benefit equally from glossing, and that language proficiency is one of the factors that influence the effects of glossing. Therefore, the control group's proficiency level could explain their superior performance over the low-density group.

The unexpected performance of the no-gloss condition in the reading comprehension could also be explained through the Involvement Load Hypothesis (Laufer \& Hulstijn, 2001). According to the hypothesis, a higher level of processing load can result in better learning. The bolded target words could have acted as prompts for the no-gloss participants to treat the text passages where the textual enhancement occurred as important and hence to put effort into their interpretation. This could have increased their processing involvement, which could have led to a deeper processing of the text. As proposed in the realm of vocabulary acquisition by Schmitt (2008), learning is maximized when learners have increased amount of engagement with lexical items. It is safe to assume that this theory could be extrapolated to intake of content, which could explain the superior performance of the no-gloss condition over the low-density condition. Having said that, literature has also shown that the more quickly a reader can access the semantic meanings, the deeper the text comprehension (Israel \& Duffy, 2009). Mezynski (1983, as cited in Israel \& Duffy, 2009) has also posited that "comprehension is a function of a reader's ability to efficiently locate and access word meanings when reading" (p.325). Also, as discussed in the Literature Review section, knowing word meaning is instrumental to reading comprehension. Thus, these theories could explain why comprehension was the best for the high-density condition.

Consistent with the theory that vocabulary is central for comprehension, a general trade-off effect was not found between vocabulary uptake and reading comprehension. This confirms Rott's (2007) claim, that glossing aids word learning while triggering comprehension of a text, without depleting the cognitive resources for either one. However, there seemed to be a trade-off effect between the uptake of target words that were glossed, and those that were unglossed. The results revealed that utilising glossing renders the vocabulary in the un-glossed passage as less important to the readers. It seems that the words that were glossed were perceived as more important to the learners as opposed to when they were only textually enhanced. In short, the study suggests that when input enhancements are utilised, be it glossing or textual enhancements only, this will increase the salience of the manipulated words but possibly at the expense of other potentially useful lexical items in the text.

Another goal of the present study was to investigate whether there would be a trade-off effect between the comprehension of idea units containing a glossed target word and the comprehension of idea units containing an unglossed target word. As shown by their raw scores, participants in both the high-density and low-density conditions performed the best on comprehension questions concerning idea units that contained a glossed target word, compared to the other questions. An interaction that approaches significance level further hinted at the possibility that readers' attention and retention of glossed idea units were at the expense of un-glossed idea units. The no-gloss participants' raw scores across the three sets of questions did not differ that much. Since none of the target words were glossed, the participants did not have to allocate their attention to any particular idea units. Their attention was still captured by the textual enhancement (i.e., bolded target words), but it was spread evenly across the passages, without being usurped by the glossing. Thus, their retention of idea units was relatively similar. The participants in the low-density condition, by contrast, performed much more poorly on the questions related to un-glossed than glossed passages. It is likely that they dwelt relatively long on the latter during reading and as a result invested less time on the other parts of the text. Essentially the same finding was reported by Rott and William (2003), who found that readers direct their attention to propositions containing word interventions while passing over propositions without interventions.

In sum, the results have suggested that glossing facilitates both incidental word learning and comprehension even when there is a high-density of glossed target words. However, while learners' cognitive and attentional resources could be spread between vocabulary uptake and reading comprehension, it seemed that insufficient resources were left for the intake of idea units without a glossed target word. Further, the findings also revealed that the uptake of glossed words were at the expense of vocabulary that was not glossed.

\section{Limitations and Future Research}

A replication with a larger number of participants would improve the finding's robustness and enable further generalizations to be made. The findings of the current study would also have been strengthened if the participants had been more homogenous in terms of level of proficiency.

Due to the length of the texts employed in the present study, only 12 questions could be used to measure the learners' comprehension. Though this number is higher compared to the other aforementioned studies, it has to be borne in mind that for the low-density condition, there were only four questions asked each for idea units that contained a glossed 
target word, idea units that contained an un-glossed target word, and idea units did not contain target words. It would be interesting to investigate whether the same results would emerge if participants read longer texts and take a reading comprehension test with more items. However, this would probably necessitate using older participants. Thus, another fruitful area for investigation would be looking at how older learners divide their attention when differing amounts of glossing are employed.

Another future research avenue involves the use of online processing measures, such as eye-tracking data. Studies that employed eye-tracking could provide valuable insights as to the effects of glossing on learners' attention. Winke's (2013) study, which is a replication of Lee's (2007) study on textual enhancement, is a good example of how eyetracking can be used to triangulate off-line and on-line data. Winke's (2013) eye-movement data confirmed that textually enhanced elements attract learners' attention, but, unlike Lee's (2007) study, the post-reading tests revealed no evidence of a trade-off effect between the learning of target forms and text comprehension. Thus, eye-movement data could lead to a richer understanding of the impact of glossing on the noticing of target words and their meaning, and the distribution of learners' attention.

\section{Conclusion}

The purpose of the current study was to continue the investigation of the effects of differing densities of glossing on both incidental vocabulary learning and comprehension (i.e., short term retention of idea units). In essence, this study sought to probe whether differing densities of glossing would bring about a two-fold trade-off effect; the first being between vocabulary uptake and comprehension, and the second being between comprehension of an idea unit containing a glossed target word, and those that did not contain a target word. In addition, the study also looked at whether or not glossing detracts from uptake of vocabulary from idea units that were un-glossed.

The investigation yielded several findings. Firstly, the results supported the idea that glossing positively affects incidental vocabulary learning. The higher the density of glossed target words, the more words were learned by the learners. Secondly, glossing also seemed to have a positive effect on reading comprehension. Contrary to the initial assumption, a higher density of glossed target words facilitated, instead of hindered comprehension. The results indicated that there was no-trade off effect between vocabulary uptake and comprehension (and retention) of idea units. Somewhat surprising also was the finding that learners' intake of idea units seemed to be positively enhanced just through textual enhancements, without the provision of glossing. It was acknowledged, though, that a variable such as learners' proficiency level might have influenced the results. Other plausible explanations, such as the Involvement Load Hypothesis, were also explored. Thirdly, the results hinted that incorporating glosses in some parts of the texts resulted in a trade-off effect between the intake of idea units containing a glossed word, and intake of idea units that did not contain a glossed word. It was also found that incorporating glossing in some passages detracted from the uptake of target words in passages that were not glossed. Lastly, the results also suggested that incorporating textual enhancements throughout the text resulted in learners distributing their attention quite evenly among the passages.

The current investigation provides insights that are relevant for ESL teachers who commonly employ glossing. The first obvious recommendation is for teachers to continue the use of glosses for the purpose of incidental vocabulary learning. The results of the current study also seem to suggest teachers to incorporate glossed target words in a way that global text comprehension will be encouraged. Put differently, teachers should be aware of the distribution of glossed target words throughout a text. Being selective of the placement of the glossed target words could ensure that passages that are of importance are not rendered as unimportant to the learners. In addition, consistency in employing input enhancement in a text could also ensure that all the target words will receive the same amount of attention. Lastly, teachers could devise activities that allow for sequential rather than concurrent learning to take place. A heightened level of awareness, coupled with cognitive processes that are not overburdened, would ensure that more learning will take place.

\section{Acknowledgements}

I would like to thank Frank Boers for his guidance and support, as well as Christye Majuddin for her help with data collection. The inferential statistics were computed at http://vassarstats.net/.

\section{References:}

Barcroft, J. (2002). Semantic and structural elaboration in L2 lexical acquisition. Language Learning, 52(2), $323-363$.

Cheng, Y., \& Good, R. L. (2009). L1 glosses: Effects on EFL learners' reading comprehension and vocabulary retention. Reading in a Foreign Language, 21(2), 119-142.

Chen, Q., \& Donin, J. (1997). Discourse processing of first and second language biology texts: Effects of language proficiency and domain-specific knowledge. Modern Language Journal, 81(2), 209-227.

Cowan, N. (2005). Working memory capacity. New York: Psychology Press.

Davis, N. (1989). Facilitating effects of marginal glosses on foreign language reading. The Modern Language Journal, 73(1), 41-48.

Ekhert, J., \& Takavoli, P. (2012). The effects of word exposure frequency and elaboration of word processing on incidental L2 vocabulary acquisition through reading. Language Teaching Research, 16(2), 227-252. 
Ellis, N. (2001). Memory for language. In P. Robinson (Ed.), Cognition and second language instruction (pp. 33-68). Cambridge: Cambridge University Press.

Freebody, P., \& Anderson, R. C. (1983). Effects of vocabulary difficulty, text cohesion, and schema availability on reading comprehension. Reading Research Quarterly, 18(3), 277-294.

Godfroid, A., Boers, F., \& Housen, A. (2013). An eye for words: Gauging the role of attention in L2 vocabulary acquisition by means of eye-tracking. Studies in Second Language Acquisition, 35(3), 483-517.

Holley, F. M., \& King, J. K. (1971). Vocabulary glosses in foreign language reading material. Language Learning, 21(2), 213-219.

Hu, M., \& Nation, I. S. P. (2000). Vocabulary density and reading comprehension. Reading in a Foreign Language, 13(1), 403-430.

Israel, S. E., \& Duffy, G. G. (2009). Handbook of research on reading comprehension. New York: Routledge.

Jacobs, G. M. (1994). What lurks in the margin: Use of vocabulary glosses as a strategy in second language reading. Issues in Applied Linguistics, 5(1), 115-137.

Jacobs, G. M., Dufon, P., \& Hong, F. C. (1994). L1 and L2 vocabulary glosses in L2 reading passages: Their effectiveness for increasing comprehension and vocabulary knowledge. Journal of Research in Reading, 17(1), 19-28.

Johnson, P. (1982). Effects on reading comprehension of building background knowledge. TESOL Quarterly, 16(4), 503-516.

Joyce, E. E. (1997). Which words should be glossed in L2 reading materials? A study of first, second, and third semester French students' recall. Pennsylvania Language Forum, 69, 58-64.

Ko, M. H. (2005). Glosses, comprehension and strategy use. Reading in a Foreign Language, 17(2), 125-143.

Ko, M. H. (2012). Glossing and second language vocabulary learning. TESOL Quarterly, 46(1), 56-79.

Laufer, B., \& Hulstijn, J. (2001). Incidental vocabulary acquisition in a second language: The construct of task-induced involvement. Applied Linguistics, 22(1), 1-26.

Lee, S. K. (2007). Effects of textual enhancement and topic familiarity on Korean EFL students' reading comprehension and learning passive form. Language Learning, 57(1), 87-188.

Lee, J., \& VanPatten, B. (1995). Making communicative language teaching happen. Boston: McGraw Hill.

Leow, R. P. (1997). Attention, awareness, and foreign language behavior. Language Learning, 47(3), 467-505.

Leow, R. P. (2001). Do learners notice enhanced forms while interacting with the L2? An online and offline study of the role of written input enhancement in L2 reading. Hispania, 84(3), 496-509.

Nagy, W. E., Herman, P., \& Anderson, R. C. (1985). Learning words from context. Reading Research Quarterly, 20(2), 233-253.

Nation, I. S. P. (2002). Learning vocabulary in another language. The Cambridge Applied Linguistics Series: Cambridge University Press.

Overstreet, M. (1998). Text enhancement and topic familiarity: The focus of learners' attention. Spanish Applied Linguistics, 2, 229-258.

Rosa, E., \& O’Neill, M. (1999). Explicitness, intake and the issue of awareness: Another piece to the puzzle. Studies in Second Language Acquisition, 21(4), 511-556.

Rott, S., \& Williams, J. (2003). Making form-meaning connections while reading: A qualitative analysis of the effect of input and output tasks on word learning. Reading in a Foreign Language, 15, 45-74.

Rott, S. (2007). The effects of frequency of input-enhancements on word learning and text comprehension. Language Learning, 57(2), 165-199.

Schmidt, R. (1994). Implicit learning and the cognitive unconscious: Of artificial grammars and SLA. In N. Ellis (Ed.), Implicit and explicit learning of languages (pp. 165-209). London: Academic Press.

Schmidt, R. (1995). Consciousness and foreign language learning: A tutorial on attention and awareness in learning. In R. Schmidt (Ed.), Attention and awareness in foreign language learning (pp. 1-63). Honolulu, HI: University of Hawai i, National Foreign Language Resource Center.

Schmidt, R. (2001). Attention. In P. Robinson (Ed.), Cognition and second language instruction (pp. 3-32). Cambridge: Cambridge University Press.

Schmitt, N. (2008). Instructed Second Language Vocabulary Learning. Language Teaching Research 12(3), 329-363.

Sharwood Smith, M. (1986). Comprehension versus acquisition: Two ways of processing input. Second Language Research, 7(3), 188-132.

Skehan, P. (1996). Second language acquisition research and task-based instruction. In J. Willis and D. Willis (Eds.), Challenge and change in language teaching (pp. 17-30). Oxford: Heinemann.

VanPatten, B. (1996). Input processing and grammar instruction: Theory and research. Norwood, NJ: Ablex. 
Waring, R.., \& Takaki, M. (2003). At what rate do learners learn and retain new vocabulary from reading a graded reader? Reading in a Foreign Language, 15(2), 130-163.

Watanabe, Y. (1997). Input, intake, and retention: Effects of increased processing on incidental learning of foreign language vocabulary. Studies in Second Language Acquisition, 19(3), 287-307.

Webb, S. (2007). The effects of repetition on vocabulary knowledge. Applied Linguistics, 28(1), 46-65.

Webb, S. (2010). Using glossaries to increase the lexical coverage of television programs. Reading in a Foreign Language, 22(1), 201-221.

Winke, P. M. (2013). The effects of input enhancement on grammar learning and comprehension: A modified replication of Lee (2007) with eye-movement data. Studies in Second Language Acquisition, 35(3), 323-352.

Wong, W., \& Simard, D. (2000). La saisie, cette grande oubliée! Acquisition et interaction en langue étrangere, 14, 5986.

Yoshii, M. (2006). L1 and L2 glosses: Their effects on incidental vocabulary learning. Language Learning \& Technology, 10(3), 85-10.

\section{Appendices}

Appendix 1: The reading comprehension texts.

\section{Reading comprehension text for the high-density condition:}

\section{$\underline{\text { Passage } 1}$}

The durian or better known as the king of fruits is very popular among the locals and some tourists. Not all tourists like the durian because of its strong smell. The jungle variety from the hills is the most popular. It tastes and smells better. It is also much cheaper than the other varieties.

This type of durian is collected by the orang asli in the jungles of Ulu Geroh and nearby Ulu Kampar and sold to middlemen. These middlemen then send out the durians as far away as Kuala Lumpur and Selangor. Jungle durians come into season twice annually.

Jungle durians are better because they come from trees that developed from seeds and not through the grafting process. The orang asli use only natural fertilisers and not pesticides on their durian trees. They could earn between RM1.00 and RM5.00 for each fruit depending on the size. They are able to collect about 80 to 100 fruits a day and that means they could earn an average of RM80.00 a day.

The next time you wish to get good durians, do try the jungle variety. You will surely taste the difference and once you have tasted it, you will come back for more.

$$
\begin{aligned}
& \text { Word Aid } \\
& \text { middlemen - people who buy and sell fertiliser - something that helps plants grow } \\
& \text { annually - yearly } \\
& \text { to develop - to grow } \\
& \text { to graft - to join (the bud of a plant to another plant) }
\end{aligned}
$$

\section{Passage 2}

KUALA LUMPUR - Thousands of Malaysian Indians gave fruits, flowers and ponggal (sweet rice) to the sun god Syura yesterday to give thanks for a big harvest.

New mud pots with attractive designs were used to boil milk and make the ponggal. At the Nageswari Amman Temple in Bangsar, when the boiling rice and milk poured out to the east, the temple's chief priest Sivaredivindran Sivachariar said the direction the milk poured out was especially good.

"It means that everyone will enjoy a good year," he said, adding that if the milk poured out towards the north, it would be dreadful for farmers as it would bring a lot of rain.

The Ponggal celebration is a happy celebration for the Indian people. In Bangsar, Brickfields and Sentul, mud pots and sugarcane stalks get sold briskly.

Indian restaurants around the Klang Valley served vegetarian dishes and a variety of sweet cakes. A lot of Indians went on a vegetarian diet a number of days before the Ponggal celebration.

$$
\begin{aligned}
& \text { Word Aid } \\
& \text { attractive }- \text { beautiful } \\
& \text { dreadful - very bad } \\
& \text { briskly - quickly }
\end{aligned}
$$




\section{$\underline{\text { Passage } 1}$}

The durian or better known as the king of fruits is very popular among the locals and some tourists. Not all tourists like the durian because of its strong smell. The jungle variety from the hills is the most popular. It tastes and smells better. It is also much cheaper than the other varieties.

This type of durian is collected by the orang asli in the jungles of Ulu Geroh and nearby Ulu Kampar and sold to middlemen. These middlemen then send out the durians as far away as Kuala Lumpur and Selangor. Jungle durians come into season twice annually.

Jungle durians are better because they come from trees that developed from seeds and not through the grafting process. The orang asli use only natural fertilisers and not pesticides on their durian trees. They could earn between RM1.00 and RM5.00 for each fruit depending on the size. They are able to collect about 80 to 100 fruits a day and that means they could earn an average of RM80.00 a day.

The next time you wish to get good durians, do try the jungle variety. You will surely taste the difference and once you have tasted it, you will come back for more.

\section{Word Aid \\ middlemen - people who buy and sell \\ pesticide — something that kills insects}

fertiliser - something that helps plants grow average - more or less

\section{Passage 2}

KUALA LUMPUR - Thousands of Malaysian Indians gave fruits, flowers and ponggal (sweet rice) to the sun god Syura yesterday to give thanks for a big harvest.

New mud pots with attractive designs were used to boil milk and make the ponggal. At the Nageswari Amman Temple in Bangsar, when the boiling rice and milk poured out to the east, the temple's chief priest Sivaredivindran Sivachariar said the direction the milk poured out was especially good.

"It means that everyone will enjoy a good year," he said, adding that if the milk poured out towards the north, it would be dreadful for farmers as it would bring a lot of rain.

The Ponggal celebration is a happy celebration for the Indian people. In Bangsar, Brickfields and Sentul, mud pots and sugarcane stalks get sold briskly.

Indian restaurants around the Klang Valley served vegetarian dishes and a variety of sweet cakes. A lot of Indians went on a vegetarian diet a number of days before the Ponggal celebration.

\section{Word Aid}

attractive - heautiful

\section{Reading comprehension text for the no-gloss condition:} $\underline{\text { Passage } 1}$

The durian or better known as the king of fruits is very popular among the locals and some tourists. Not all tourists like the durian because of its strong smell. The jungle variety from the hills is the most popular. It tastes and smells better. It is also much cheaper than the other varieties.

This type of durian is collected by the orang asli in the jungles of Ulu Geroh and nearby Ulu Kampar and sold to middlemen. These middlemen then send out the durians as far away as Kuala Lumpur and Selangor. Jungle durians come into season twice annually.

Jungle durians are better because they come from trees that developed from seeds and not through the grafting process. The orang asli use only natural fertilisers and not pesticides on their durian trees. They could earn between RM1.00 and RM5.00 for each fruit depending on the size. They are able to collect about 80 to 100 fruits a day and that means they could earn an average of RM80.00 a day.

The next time you wish to get good durians, do try the jungle variety. You will surely taste the difference and once you have tasted it, you will come back for more.

Passage 2

KUALA LUMPUR - Thousands of Malaysian Indians gave fruits, flowers and ponggal (sweet rice) to the sun god Syura yesterday to give thanks for a big harvest.

New mud pots with attractive designs were used to boil milk and make the ponggal. At the Nageswari Amman Temple in Bangsar, when the boiling rice and milk poured out to the east, the temple's chief priest Sivaredivindran Sivachariar said the direction the milk poured out was especially good.

"It means that everyone will enjoy a good year," he said, adding that if the milk poured out towards the north, it would be dreadful for farmers as it would bring a lot of rain.

The Ponggal celebration is a happy celebration for the Indian people. In Bangsar, Brickfields and Sentul, mud pots and sugarcane stalks get sold briskly.

Indian restaurants around the Klang Valley served vegetarian dishes and a variety of sweet cakes. A lot of Indians went on a vegetarian diet a number of days before the Ponggal celebration. 
Appendix 2: The vocabulary pre-test.

Name:

Class:

Instructions: There are 20 questions. Please match the English word with the correct meaning. Circle the correct answer.
1. plentiful
(a) a lot
(b) average
(c) small
(d) enough
(e) I don’t know

2. annually
(a) weekly
(b) daily
(c) monthly
(d) yearly
(e) I don't know
3. to earn
(a) to lose
(b) to give
(c) to get
(d) to miss
(e) I don't know
4. to develop
(a) to take
(b) to break
(c) to grow
(d) to send
(e) I don't know
5. to offer
(a) to get
(b) to give
(c) to grow
(d) to take
(e) I don't know

\section{6. middlemen}
(a) people who buy
(b) people who buy and sell
(c) people who sell
(d) people who stand in the middle
(e) I don't know

\section{7. briskly}
(a) quickly
(b) quietly
(c) slowly
(d) regularly
(e) I don't know

\section{8. fertiliser}
(a) something that kills bacteria
(b) something that kills insects
(c) something that protects animals
(d) something that helps plants grow
(e) I don't know 

rage
(a) rare
(b) more
(c) more or less
(d) less
(e) I don't know

\section{0. earthen}
(a) mud
(b) metal
(c) plastic
(d) stick
(e) I don't know

\section{1. pesticide}
(a) something that helps plants grow
(b) something that gives nutrition
(c) something that kills insects
(d) something that kills weeds
(e) I don't know

\section{2. definitely}
(a) maybe
(b) surely
(c) seriously
(d) kindly
(e) I don't know
13. dreadful
(a) very bad
(b) exciting
(c) wonderful
(d) normal
(e) I don't know
14. to graft
(a) to grade
(b) to guess
(c) to divide
(d) to join
(e) I don't know

15. to distribute
(a) to send out
(b) to collect
(c) to join
(d) to hold
(e) I don't know
16. species
(a) type
(b) spice
(c) glass
(d) example
(e) I don't know

\section{7. attractive}
(a) expensive
(b) beautiful
(c) boring
(d) creative
(e) I don't know 

18. occasion
(a) accident
(b) assembly
(c) event
(d) examination
(e) I don't know

\section{9. to overflow}
(a) to pour out
(b) to kick out
(c) to take out
(d) to put out
(e) I don't know
20. community
(a) content
(b) instrument
(c) tool
(d) society
(e) I don't know

Appendix 3: The reading comprehension test.

\section{For each question, circle the correct answer.}

Questions 1-6 are on Passage 1

1. The jungle durian variety is from
A. the valleys
C. the estates
B. the hills
D. the plantations

2. What is the job of the middlemen?
A. To buy the jungle durians from the orang asli in Ulu Geroh and Ulu Kampar
B. To buy the jungle durians from the orang asli and to sell them in places like Kuala Lumpur and Selangor
C. To sell the jungle durians to the orang asli in Ulu Geroh and Ulu Kampar
D. To sell the jungle durians in places like Kuala Lumpur and Selangor

3. How often does the jungle durian come into season?
A. twice weekly
C. twice yearly
B. twice monthly
D. twice fortnightly
4. Jungle durians come from
A. trees that grow from seeds
B. trees that were grown by the middlemen in Ulu Keroh and Ulu Kampar
C. trees that grow through the joining of their buds to another plant
D. trees that grow in the valleys of Ulu Keroh and Ulu Kampar

5. Which of the following is true about the jungle durian?
A. fertilisers are used to help the durians grow
B. they are collected by the middlemen
C. they are more expensive than other types of durian
D. they have a lot of chemicals that help kill insects 
6. The orang asli can earn
A. more or less RM100 a day
B. RM180 a day
C. more or less RM80 a day
D. RM100 a day

\section{Questions 7-12 are on Passage 2}

7. Syura is the name of the
A. sun God
C. earth God
B. star God
D. harvest God

8. According to the news report, what kind of pots were used to boil the milk and make the Ponggal?
A. mud pots with Ponggal designs
B. mud pots with floral designs
C. mud pots with beautiful designs
D. mud pots with the same design as the temple

9. According to the temple priest, what does it mean if the milk poured out to the north?
A. it is a sign to offer more fruits, flowers and Ponggal to God
B. it is a very bad sign because there will be a lot of rain
C. it is a sign that the Indians should go on a vegetarian diet
D.it is a very good sign because there will be little rain

10. What happens to the mud pots and sugarcane stalks during Ponggal?
A. they are sold quickly
B. they are offered to God
C. they are not sold in the temple
D. they are used to make Ponggal

11. What do the Indian restaurants in Klang Valley serve during Ponggal?
A. sugarcane stalks and vegetarian dishes
B. Ponggal and vegetarian dishes
C. Ponggal and sugarcane stalks
D. sweet cakes and vegetarian dishes

12. According to the news report, a lot of Indians
A. went on a vegetarian diet on the day of Ponggal
B. became vegetarian after the Ponggal celebration
C. went on a vegetarian diet before the Ponggal celebration
D. are vegetarians throughout the year

Appendix 4: The vocabulary posttest

Instructions: There are 20 questions. Please match the English word with the correct meaning. Circle the correct answer.

\section{1. fertiliser}
(a) something that helps plants grow
(b) something that kills insects
(c) something that kills bacteria
(d) something that protects animals
(e) I don't know 

2. earthen
(a) stick
(b) metal
(c) plastic
(d) mud
(e) I don't know
3. annually
(a) daily
(b) weekly
(c) yearly
(d) monthly
(e) I don't know
4. species
(a) glass
(b) type
(c) spice
(d) example
(e) I don't know
5. to offer
(a) to grow
(b) to give
(c) to take
(d) to get
(e) I don't know
6. occasion
(a) event
(b) examination
(c) accident
(d) assembly
(e) I don't know

7. middlemen

(a) people who sell

(b) people who buy and sell

(c) people who buy

(d) people who stand in the middle

(e) I don't know
8. to overflow
(a) to put out
(b) to take out
(c) to kick out
(d) to pour out
(e) I don't know

\section{9. plentiful}
(a) small
(b) enough
(c) a lot
(d) average
(e) I don't know

\section{0. community}
(a) tool
(b) instrument
(c) content
(d) society
(e) I don't know

11. to develop
(a) to send
(b) to take
(c) to grow
(d) to break
(e) I don't know 

12. average
(a) more
(b) more or less
(c) rare
(d) less
(e) I don't know
13. definitely
(a) seriously
(b) kindly
(c) maybe
(d) surely
(e) I don't know

14. to graft

(a) to divide

(b) to join

(c) to grade

(d) to guess

(e) I don't know

\section{5. to earn}
(a) to get
(b) to miss
(c) to lose
(d) to give
(e) I don't know

\section{6. dreadful}
(a) wonderful
(b) normal
(c) very bad
(d) exciting
(e) I don't know

\section{7. briskly}
(a) quickly
(b) slowly
(c) quietly
(d) regularly
(e) I don't know

\section{8. pesticide}
(a) something that gives nutrition
(b) something that helps plants grow
(c) something that kills weeds
(d) something that kills insects
(e) I don't know

\section{9. to distribute}
(a) to send out
(b) to join
(c) to collect
(d) to hold
(e) I don't know

\section{0. attractive}
(a) creative
(b) boring
(c) beautiful
(d) expensive
(e) I don't know 